Área Abierta. Revista de comunicación

audiovisual y publicitaria

ISSN: 1578-8393 / ISSNe: 1578-8393

\title{
El arquetipo de viaje en el cine moderno de terror: la historia de una subversion
}

\author{
Rocío Alés Fernández ${ }^{1}$
}

Recibido: 21 de marzo de 2017 / Aceptado: 19 de septiembre de 2017

Resumen. El arquetipo del viaje ostenta un importante papel en el imaginario cultural de Estados Unidos. A lo largo del siglo XIX y principios del XX, la literatura estadounidense centraría gran parte de sus argumentos en el viaje figurado y metafórico, al igual que muchos de los géneros del Hollywood clásico y genuinamente norteamericanos como el western. Con el paso del tiempo, en el contexto de la crisis política, social y cultural que atravesarían los Estados Unidos a finales de la década de los sesenta, el cine moderno de terror se apropiaría de este arquetipo para llevar a cabo su definitiva subversión. En el siguiente artículo profundizaremos sobre la importancia del arquetipo del viaje en el imaginario cultural estadounidense y su posterior fractura en momentos de crisis social, a través del estudio de su evolución en la literatura y los géneros cinematográficos.

Palabras clave: Arquetipo de viaje; cultura estadounidense; cine de terror rural; estereotipo de América profunda

\section{[en] The Archetype of the Journey in Modern Horror Films: The History of a Subversion}

\begin{abstract}
The archetype of the journey has an important role in the imaginary cultural heritage of the United States. Throughout the late 19th and early 20th centuries, American literature would focus much of its arguments on the figurative and metaphorical journeys, like many of the classic Hollywood genres and those genuinely American such as the western. Over the years, in the context of the political, social and cultural crises that the United States would go through during the late sixties, modern horror cinema would appropriate of this archetype to carry out its final subversion. In the following article, we will deepen on the importance of the archetype of the journey within the American cultural imaginary and its subsequent fracture in times of social crisis, through the study of its evolution in the literature and film genres. The use of a multidisciplinary methodology will allow us to approach the subject from a perspective that includes the historical, artistic and social realities.

Keywords: The Journey Archetype; American Culture; Rural Terror Films; The Deep America Stereotype
\end{abstract}

Sumario. 1. Introducción, conceptualización y metodología. 2. Precedentes históricos, literarios y cinematográficos. 3. La subversión del arquetipo del viaje en el cine de "terror rural". 4. Conclusiones. 5. Bibliografía

1 Investigadora independiente

E-mail: rocioalesf@gmail.com 
Cómo citar: Alés Fernández, R. (2018). El arquetipo de viaje en el cine moderno de terror: la historia de una subversión, en Área Abierta. Revista de comunicación audiovisual y publicitaria 18 (3), 405-419. http://dx.doi.org/10.5209/ARAB.55521

\section{Introducción, conceptualización y metodología}

La manifiesta necesidad de retorno a los orígenes que caracteriza a la sociedad estadounidense y su particular devenir histórico, explican la importancia de la idea simbólica de viaje en su tradición cultural (Barrio, 2004: 183-185). Conocida por definición como una construcción mitológica cuyo sentido principal radica en la búsqueda de la identidad y considerada uno de los principales mitos de la literatura universal, este pueblo ha tenido en este arquetipo uno de sus temas capitales.

Explotado por las letras estadounidenses desde el siglo XIX hasta nuestros días, se convertiría con el tiempo en uno de los grandes temas cinematográficos de Hollywood (Balló y Pérez, 1995: 170). De forma específica, el cine de terror moderno (Losilla, 1993: 142-143) realizaría diferentes usos de esta temática: unas veces como recurso a través del cual vertebrar la narración y otras como concepto argumental más profundo. A través de la idea de viaje entendida como compendio cultural, legendario y mitológico, el cine de "terror rural" plasmaría una nueva visión del choque entre los valores tradicionales y los nuevos, continuando de esta manera el debate que divide a la sociedad estadounidense desde sus orígenes (Degler, 1986: 34).

Este subgénero, contextualizado en zonas rurales de Estados Unidos y del que forman parte filmes tan señeros como La matanza de Texas (The Texas Chainsaw Massacre, Tobe Hooper, 1974) o Las colinas tienen ojos (The Hills Have Eyes, Wes Craven, 1977), emerge en la etapa moderna del cine de terror abandonando todo componente sobrenatural para dar la vuelta de tuerca definitiva al llamado estereotipo de la "América profunda": un concepto global que hace referencia a todas aquellas zonas rurales de Estados Unidos que, por circunstancias históricas, culturales y económicas, han quedado al margen de las grandes urbes, poniendo en práctica un estilo de vida caracterizado por su marginalidad y miseria (Isenberg, 2016: 135-140) que contrasta en gran medida con el de las sociedades modernas.

En el presente artículo trataremos de indagar en la transformación que de este arquetipo realizaría el cine de terror norteamericano en su etapa moderna (De Fez, 2007: 21-30), específicamente en el subgénero que hemos denominado cine de "terror rural", un concepto que proponemos al tratarse de filmes contextualizados eminentemente en zonas campestres, en clara oposición con el mundo urbano. Emplearemos una metodología multidisciplinar que fusiona la vertiente histórica (el viaje colonizador de los puritanos), la social (en tanto a la existencia de una crisis que sirve de catalizador), la artística (estudio de los precedentes literarios y cinematográficos que forjan el arquetipo antes de su subversión) sin dejar de lado la vertiente antropológica (la idea de "América profunda" como antítesis del mundo civilizado y metáfora de las reminiscencias de brutalidad en el mundo rural).

Me gustaría destacar, por último, cómo los títulos seleccionados van a atender a diversas tipologías de producción: filmes comerciales, largometrajes con vocación experimental y alternativa, telefilmes y exploitations (Schaefer, 1999: 17-21), de cara 
a ofrecer un panorama general de la subversión del arquetipo de viaje en el género de terror moderno estadounidense.

\section{Precedentes históricos, literarios y cinematográficos}

\subsection{Precedentes históricos}

La llegada del Mayflower a la Costa Este el once de noviembre de 1620 traería consigo la fundación de las "trece originales" y el punto de partida de la actual nación ${ }^{2}$. Tras una serie de problemas iniciales, la comunidad puritana arribaría a las costas de Massachusetts para fundar la colonia de Plymouth (Bradford, 1994: 672), llamada así en honor a la ciudad británica desde la cual había partido esta mítica expedición (Platt, 1973: 50-55). La idealización a la que a menudo ha sido sometida la propia historia de Estados Unidos obvia el lapso de tiempo comprendido entre la llegada a las costas del Nuevo Mundo hasta la fundación de la primera colonia, ignorando a menudo cómo estos viajeros, en lugar de un Nuevo Edén, encontraron una inmensidad natural aterradora y en apariencia infinita. Buena prueba de ello es la empalizada que crearon como protección ante nativos hostiles y colonos enemigos (Trocmé, 1983: 13-15).

Por tanto, ya en este primer momento, los padres pioneros sufrieron un choque entre la idealización del Nuevo Mundo como tierra de segundas oportunidades y la dureza de las condiciones de vida que allí encontraron (Gorman, 1958: 20). La mentalidad puritana, que entendía los peligros de este viaje como una prueba iniciática cuya recompensa sería alcanzada por aquellos que perseverasen en la lucha frente al mal, sería puesta en tela de juicio por los llamados Pilgrims Dissenters, colonos disidentes ajenos a la ortodoxia de unos pioneros que habían llevado sus creencias al extremo durante el período de la "caza de brujas" (Reis, 1999: 70). Los colonos ajenos a esta forma de vida fundarían nuevos asentamientos más acordes con sus creencias, construyéndose de forma paralela otras tantas colonias de emigrantes procedentes de diferentes lugares de Europa (Middleton, 1996: 104-120).

Posteriormente, ya en el siglo XIX, el pueblo norteamericano emprendería la expansión de la frontera hacia el Oeste, un viaje asociado nuevamente a la búsqueda de un Nuevo Edén, que se perpetuaría en el imaginario estadounidense como la auténtica gesta nacional. Estas tierras salvajes, indómitas e inexploradas, estarían vinculadas a la búsqueda de libertad y al reencuentro con lo primitivo como antítesis del ya urbanizado Este (Abella, 1990: 50). De este modo, la idea de Oeste quedaría asociada al viaje como fuente de aventuras y búsqueda del porvenir en un entorno salvaje y no explotado.

2 Sin perder de vista la ocupación sobre parte del territorio Norteamericano del Imperio Español, acotaremos sin embargo este apartado a las "trece originales", nombre con el que la historiografía denomina a las posesiones coloniales de Gran Bretaña en la Costa Atlántica de América del Norte comprendidas entre Nueva Escocia y Florida, las cuales a finales del siglo XVIII se unificaron bajo un gobierno independiente para crear los actuales Estados Unidos (Foster, 2013: 171). 


\subsection{Precedentes literarios}

En una fase primitiva de la historia norteamericana se observa ya de forma clara esa tendencia hacia la búsqueda incansable de nuevas oportunidades a través de dos tipos de viaje: el viaje geográfico, con el traslado inicial de los pioneros ingleses a la costa Este del Norte de América y la posterior ampliación de la frontera hacia la costa del Pacífico, y el viaje metafórico en cuanto a la búsqueda constante de una identidad como nación (Delgado y Clemente, 2013: 8-20). El trasvase literario de estas circunstancias históricas darían forma al arquetipo del viaje como construcción, que posteriormente se popularizaría y afianzaría en la memoria colectiva por otros medios como el cinematográfico.

Si realizamos un breve repaso por la retórica del viaje en la literatura norteamericana, observamos cómo los primeros escritores reseñables norteamericanos como Nathaniel Hawthorne (1804-1864), Edgar Allan Poe (1809-1849) o Herman Melville (1819-1891), centrarían sus intereses en cuestiones de índole simbólica y moral, empleando el símil del viaje como camino interior (Conn, 1998: 120-129). La segunda generación de autores estadounidenses plasmaría, a través del realismo literario, la realidad de este recién estrenado pueblo. De entre sus representantes cabe destacar a Mark Twain (1835-1910) y su novela Las aventuras de Huckleberry Finn (Adventures of Huckleberry Finn, 1884), obra articulada en torno a un viaje de búsqueda de la libertad (Emerson, 1984: 13-31). Al mismo período pertenecería la llamada "literatura de identidad nacional" (Conn: 232), que abriría principalmente dos vías:

Por un lado, aquella narrativa fronteriza centrada en el viaje geográfico, en la que se plasmaba la dura prueba de adaptación a los territorios del Oeste realzada con ciertos tintes románticos que perpetuaban los conceptos de aventura, expansión, oportunidad y libertad (Estevez-Saá y Arriaga Flórez, 2005: 155-162); por otro lado, la literatura sureña, y de forma específica la escuela del Local Color, que haría referencia a un viaje de índole interior en el cual se reflexionaba sobre los cambios producidos tras la Guerra Civil (Manuel Cuenca, 1994: 26).

En el contexto de la modernidad literaria, autores como John Steinbeck (19021968), William Faulkner (1897-1962) o J.D. Salinger (1919-2010), criticarían la tradición familiar y social, valiéndose del viaje como recurso simbólico de búsqueda de unos personajes escindidos entre el pasado y el presente (Lamarca Margalef, 1989: 17-21). Esta nueva vía abriría el camino para los autores de la siguiente generación, los cuales ahondarían en los conceptos de soledad y desarraigo propios del hombre de postguerra. Dentro de este contexto se abrirían varios frentes creativos como la Beat Generation (Clellon, 1958: 39). El autor Jack Kerouac (1922-1969), cabeza visible de este movimiento literario, manifestaría su desapego del mundo material en On the Road (1957), una novela de carácter autobiográfico basada en una serie de viajes realizados por Kerouac y Neal Cassady entre 1947 y 1950. Los protagonistas se embarcan en un viaje hacia el Oeste en busca de la libertad implícita al sueño americano (Swartz, 1999: 40-50). Este viaje geográfico desde Cape Cod hasta Nevada y Los Ángeles, así como el viaje interior de búsqueda de los propios personajes, influenciarían enormemente a la generación contracultural de finales de los sesenta, que tomaría de los Beat numerosos ingredientes para integrarlos en su programa (Fernández Sampedro, 2008: 141-161). 


\subsection{Precedentes cinematográficos}

\subsubsection{El western}

Uno de los géneros cinematográficos clásicos que han recreado de forma reiterativa el catálogo de arquetipos sobre los que cimienta la cultura estadounidense, entre ellos el del viaje, es el western. Una vez iniciado el proceso de independencia del Nuevo Mundo con respecto a la Corona Británica, surgiría la necesidad de conquistar nuevos territorios para albergar a una segunda oleada de inmigrantes (Hawgood, 1967: 254283). Por esta y otras intenciones, durante las décadas de 1850-1860 tendría lugar una intensa propaganda con el fin de conducir en un nuevo viaje hacia el Oeste a muchos de estos nuevos norteamericanos. Esta idea ha sido sintetizada bajo el concepto de Destino Manifiesto (Horsman, 1985: 7-9), una doctrina que convertía a Estados Unidos en el pueblo elegido que había de expandir su civilización por todo el continente. A esta circunstancia se sumaría el éxodo de los granjeros del Sur que, convertidos en meros arrendatarios de sus propios terrenos, trataban de evitar el yugo impuesto por los grandes terratenientes (Hernández Alonso, 2002: 152). Estas nuevas tierras proveerían a innumerables colonos de un espacio natural ajeno a la civilización repleta de bienes naturales, pero también de la violencia que suponía la invasión a la fuerza de un lugar previamente ocupado. Esta gran epopeya en forma de viaje, así como las diversas circunstancias que lo rodearon, sería plasmada de diferentes maneras por la industria de Hollywood dentro del marco genérico del western.

Dejando de lado la realidad de los hechos históricos, este género partiría de la mitificación llevada a cabo por varios soportes artísticos, para aportar la versión definitiva de la expansión estadounidense. Tal y como apunta Georges-Albert Astre, “...el Oeste simboliza la plenitud y la abundancia, el nuevo nacimiento del hombre en una tierra libre y feliz" (Astre y Hoarau, 1976: 23), un Nuevo Edén que sería ensalzado por la tradición plástica decimonónica norteamericana, la cual se complacería en la inmensidad natural y las riquezas de estas tierras salvajes (Hughes, 2001: 147). Este proceso de mitificación de la expansión de la frontera llevado a cabo por las artes plásticas se vería apoyado por la ingente producción literaria que en el siglo XIX había centrado sus argumentos en esta parcela de la historia (Clemente Fernández, 2009: 24).

Esta lucha del hombre por encontrar un hueco en este Nuevo Edén a través de la epopeya de un viaje, sería reflejada en filmes como La caravana de Oregón (The Covered Wagon, James Cruze, 1923) y su remake Camino de Oregón (The Way West, Andrew V. McLaglen, 1967), entre otros. En estos largometrajes podemos apreciar la evolución de un género originariamente maniqueo, que derivaría en un espacio de reflexión acerca los métodos poco ortodoxos empleados en la conquista del Oeste (Altman, 2000: 60-65). En el primer caso, dos caravanas de camino a Oregón convergen en mitad del camino, uniendo fuerzas para alcanzar los territorios del Oeste. Mientras que la trama global recae en la épica de unos pioneros que luchan por alcanzar un futuro mejor, el argumento principal nos muestra la historia del triángulo amoroso entre una joven y dos estereotipados personajes masculinos. $\mathrm{La}$ caravana de Oregón se convertiría en una de las primeras películas que plasmarían 
la épica de la emigración hacia el Oeste, codificándose la idea de autenticidad que proporcionaría el rodaje en escenarios naturales.

Cuarenta años después, Camino de Oregón narra nuevamente la historia de una partida de pioneros rumbo a Oregón, en este caso liderada por el senador William J. Tadlock (Kirk Douglas), que parte de Missouri con la intención de buscar tierras más prósperas en el Oeste. Para la expedición cuenta con la ayuda del Señor Sommers (Robert Mitchum), un solitario y melancólico rastreador que velará por la seguridad de las familias y comerciantes que forman la caravana. Al tratarse de un título de la década de los sesenta y por lo tanto de un western alejado de las actitudes maniqueas debido a la propia evolución del género, apreciamos cómo los malos actos de ciertos personajes van a desembocar en una serie de desgracias colectivas como metáfora del castigo social. El broche crítico vendrá con la muerte del propio senador, el cual, a pesar de ser el líder de la expedición, es privado de alcanzar la supuesta prosperidad y libertad en las nuevas tierras.

\subsubsection{La road movie}

Al margen del western y su plasmación del viaje como metáfora del Nuevo Edén y las segundas oportunidades, otros géneros cinematográficos posteriores aportarían diferentes versiones de este arquetipo: enlazando con la ya citada Beat Generation, el viaje como búsqueda de la libertad y rechazo del sistema sería llevado a la gran pantalla en Easy Rider (Buscando mi destino) (Easy Rider, Dennis Hooper, 1969), un filme que sintetiza numerosos ingredientes de la cultura del momento y que además inaugura, junto con Bonnie and Clyde (Bonnie and Clyde, Arthur Penn, 1967), el género road movie en el contexto del Nuevo Hollywood de finales de los sesenta (Biskind, 2004: 13-15). Considerado junto con el western uno de los géneros cinematográficos norteamericanos por excelencia, posee ciertas particularidades reconocibles: su argumento se estructura en torno a un viaje de búsqueda protagonizado por un héroe o grupo de nómadas que rechazan la sociedad, los cuales recurren a los medios de transporte modernos para atravesar los inmensos territorios del país (Correa, 2006: 270-275).

La road movie actualizaría el mito del paisaje norteamericano, al evocar de forma melancólica un pasado natural que ha sido engullido por el progreso y la modernidad. De forma paralela, también constituirá un alegato a favor de los avances tecnológicos al fomentar la presencia de los medios de transporte, las vías de comunicación y la red de carreteras (Cohan, 1997: 1-17). A la inversa del trayecto realizado por los protagonistas de On the Road, Billy (Dennis Hopper) y Wyatt (Peter Fonda) arrancan en Los Ángeles teniendo en Nueva Orleans su fin de trayecto, un lugar donde esperan encontrar la libertad a través de lo material, frente a la espiritualidad por la que abogaban los personajes literarios. Easy Rider recuperaría el argumento del viaje de aventuras donde no existe un encargo específico (sólo, como en el caso de On the Road, escapar de las imposiciones del hogar), y tampoco un objetivo final definido, siendo la parte central (el viaje en sí mismo, la necesidad de movimiento, las personas que se encuentran por el camino) lo realmente importante (Balló y Pérez: 54-55). Eugenio Trías en su ensayo Drama e identidad, distingue dos modalidades de viaje y viajero: aquel que pierde su hogar temporalmente y se extravía, pero que finalmente es reconducido de vuelta a su lugar de origen en un peligroso paso a través del infierno que tiene como resultado un final feliz en contraste con una segunda 
tipología, una modalidad de viaje y viajero que el autor sitúa de forma coetánea, y que como Billy y Wyatt, hace un viaje sin finalidad en sí mismo al carecer de punto de partida y de meta (Trías, 1974: 67).

A través de esta mezcla de fascinación y rechazo hacia la cultura norteamericana, vemos cómo los personajes emprenden un viaje para escapar de la ciudad y la podredumbre social. Sin embargo, a medida que se adentran en el corazón del Sur profundo comienzan a sentir la hostilidad del pueblo local. Después de conocer a George Hanson (Jack Nicholson), un abogado alcohólico que se unirá a la epopeya, prosigue el viaje hasta Luisiana. Allí se detienen en un pequeño establecimiento de sabor rural y decadente, donde el choque entre ciudad-modernidad y campotradición se hace más patente que nunca. El resultado del encontronazo con el grupo de lugareños hostiles que encuentran en este lugar será la muerte del recién incorporado George, momento a partir del cual todo cambia para Wyatt: el que antes había sido el miembro más positivo, activo y generoso del grupo, sucumbe al desencanto generalizado, declarando el fracaso de la aventura. Este viaje de espíritu beat les conduciría a ambos directamente a esa "América profunda" asociada, como no podía ser de otra forma, al Sur de Estados Unidos, un lugar al margen de la ley en el que cualquier elemento vinculado al progreso será visto como una amenaza tangible que hay que eliminar. De este modo, Billy y Wyatt, en esta búsqueda ideal de los orígenes del pueblo norteamericano, encuentran la muerte a manos de un par de pueblerinos ${ }^{3}$ que se cruzan por su camino, que los acribillan a sangre fría, a punta de escopeta. Sobre esta asociación del Sur con el crimen o el asesinato, el crítico de cine Paul Schrader comentaría:

El villano de Hopper es el chivo expiatorio de cualquier liberal: el redneck, el sureño reaccionario de clase baja. No hay necesidad de motivar, caracterizar o desarrollar a los asesinos: el pasado del cine nos ha enseñado que los blancos pobres del Sur cometen crímenes así de atroces por que sí. Fonda ha dicho que muy bien podrían haber situado el asesinato en el Norte. Es cierto, pero eso hubiera obligado a Hopper a definir a sus villanos con mayor precisión y se habría privado de la diversión que supone fustigar el estereotipo sureño (Cueto y Weinrichter, 2004: 420).

\subsubsection{El viaje en el cine de terror clásico}

Más allá de tipologías cinematográficas ya citadas, han existido otras como el género de terror donde el viaje y los caminos han jugado un papel crucial a nivel narrativo y simbólico. Desde las primeras películas adscritas al género producidas por la Universal como Drácula (Dracula, Tod Browning, 1931), observamos cómo la adaptación del mito literario conserva la importancia del viaje, tanto en el traslado funesto que realiza Jonathan Harker a la tierra del Conde, como el del propio vampiro a la ciudad (Fernández Cuenca, 1976: 70). De este modo, el arquetipo del viaje, además de estar asociado a un desplazamiento en pro de diferentes búsquedas, puede albergar connotaciones negativas por los peligros que aguardan en él o en

3 En Estados Unidos es frecuente el uso del término redneck, un concepto que hace referencia al estereotipo del hombre blanco de bajo poder adquisitivo. Originariamente la palabra hacía referencia a aquellos trabajadores rurales que pasaban la mayor parte de su vida bajo el sol (del inglés red neck, "cuello rojo"). Hoy, sin embargo, se emplea de forma despectiva para referir al sureño blanco conservador (Huber, 1995: 145). 
el propio destino. Antes de los primeros síntomas de modernidad en el cine de terror, los argumentos de algunos títulos clásicos tendrían en el viaje el punto de inflexión de la trama: El malvado Zaroff (The Most Dangerous Game, Irving Pichel y Ernest B. Schoedsack, 1932), en la que un experto cazador de safaris llegará a una remota isla del Pacífico tras el naufragio de su barco para emprender una lucha por la supervivencia; El lobo humano (Werewolf of London, Stuart Walker, 1935), donde un viaje al Tíbet condena al Doctor Glendon (Henry Hull) a la enfermedad de la licantropía; o El barco fantasma (The Ghost Ship, Mark Robson, 1943), cuyo argumento se desarrolla plenamente en el contexto de una travesía marítima.

\subsubsection{Psicosis como precedente subversivo}

Aunque durante las primeras décadas del género encontramos numerosos ejemplos de aplicación del arquetipo del viaje y los caminos, no sería hasta la irrupción de la modernidad en el terror cuando estos recursos sean utilizados con más frecuencia y mayor carga simbólica. Psicosis (Psycho, Alfred Hitchcock, 1960), una de las principales fuentes de inspiración para los realizadores del género de terror de la década de los setenta, nos brindaría uno de los primeros ejemplos al respecto. Durante la primera parte de la historia, observamos cómo Marion Crane (Janet Leigh) se ve obligada, después de su impulso criminal, a embarcarse en un viaje sin destino fijo y sin otra intención que la de huir. En este viaje hacia el Oeste, la ruta se complica por la lluvia y los pensamientos catastróficos de su protagonista, surgiendo, como un oasis en el camino, el luminoso del Motel Bates y sus habitaciones disponibles. Sin embargo, quizás por la criminalidad de los actos de Marion, la providencia la envía directamente a los brazos de un pueblerino psicótico, Norman Bates (Anthony Perkins), que la asesina a sangre fría encarnando la personalidad de su madre muerta.

El filme de Hitchcock inauguraría una serie de vías temáticas y recursos formales que evolucionarían en manos de directores coetáneos como Robert Aldrich o Richard Fleischer, testigo que sería recogido años más tarde por los jóvenes realizadores del terror moderno influido también por los primeros experimentos gore realizados en el seno del exploitation (Planes, 2012: 78-79). Uno de estas vías argumentales sería, precisamente, el tema del viaje y cómo a través de este las víctimas van a llegar, de forma voluntaria o accidental, al foco del mal. Mientras que, en el cine de terror clásico, el monstruo, habitualmente ajeno a la sociedad, se trasladaba a esta de forma repentina y casual, Hitchcock inaugura la idea de mal como elemento endémico a la sociedad, sugiriendo que "...el mundo es horrible porque es esencialmente neurótico y por lo tanto perversamente violento" (Derry, 1977: 85). El monstruo moderno no suele movilizarse para encontrar a sus presas, sino que se cobija en el seno de esta "América profunda" a la que solo podemos acceder a través de un viaje. De este modo, a partir de Psicosis, la inmensa mayoría de argumentos del terror fílmico en general y del "terror rural" en particular se van a construir en base a este punto de partida, un viaje que tendrá un mayor o menor grado de importancia y simbolismo, tal y como veremos a continuación.

\section{La subversión del arquetipo del viaje en el cine de "terror rural"}

El argumento del filme de Dennis Hopper, vertebrado en torno al viaje realizado por 
un grupo de jóvenes en busca de la naturaleza y los orígenes, no distaría mucho en esencia de la propuesta de La matanza de Texas, título realizado varios años después en el que observamos sin embargo el desencanto y la frustración que sobrevino en la tercera y última fase del movimiento contracultural, a consecuencia de la creciente represión y la insuficiencia de los logros obtenidos (Ruiz, 2007: 46-60). Si en Easy Rider ya encontramos trazas de esa desilusión en su brusco desenlace, $L a$ matanza de Texas llevaría al extremo la idea de viaje a la "América profunda" como camino de búsqueda equivocado, subvirtiendo por completo el arquetipo de viaje estadounidense.

\subsection{La subversión del arquetipo de viaje: el viaje sin retorno.}

El uso de la metáfora del viaje como forma de alcanzar una muerte segura, y con ello la propia subversión del arquetipo tradicional, será una constante en el género de terror desde finales de los sesenta. Relacionado igualmente con el viaje y con esta ruta hacia la muerte, encontramos el concepto clásico de catábasis, nombre que define el descenso a los infiernos del héroe para completar algún tipo de misión específica. En la mitología griega encontramos cómo Orfeo atraviesa el inframundo para traer de vuelta a su amada Eurídice, viaje que veremos plasmado tanto en la tradición cristiana como en la literatura occidental en general. Este viaje se completaría habitualmente con la anábasis, el retorno necesario de este personaje al mundo de los vivos (González Serrano, 1999: 1-3). El cine de terror norteamericano de la década de los setenta abordaría de alguna manera esta metáfora del viaje como descenso a los infiernos, aunque a diferencia del concepto clásico, estaría desprovisto de retorno alguno para sus personajes. A pesar de que las motivaciones de estos viajeros son diversas y quizás no tan elevadas como la de los héroes clásicos, lo cierto es que a través de este punto de partida los personajes se adentran en un infierno del que por norma general no pueden regresar. Este paso accidental a los infiernos, en este caso en la tierra y no en su sentido sobrenatural, suele venir precedido del deseo de alcanzar un nuevo paraíso donde no exista orden, sistema ni autoridad, un ansia de retorno a ese American Dream primigenio que pondrá en tela de juicio el propio American Way of Life 4 . A consecuencia de esta pulsión, los personajes se van a topar con un lugar ajeno a la civilización, en el que la ausencia de ley ha propiciado el desarrollo de una sociedad que ha caído en la barbarie que hace siglos dejamos atrás. Todo ello se plasma en La matanza de Texas, que tiene como punto de partida el viaje de un grupo de jóvenes a lo largo de las inmensas carreteras del estado.

El argumento nos introduce in media res en el vehículo, en cualquier momento de la ruta. El guion no aporta datos específicos del viaje, ni el origen ni el destino del mismo, tan solo que el progreso (la carretera y un vehículo de motor) ha llevado a unos modernos jóvenes a lo que aparentemente parece ser un inofensivo pueblo. Más adelante, se nos suministra un poco más de información: los hermanos Hardesty,

4 Mientras que el concepto American Dream (sueño americano), utilizado por primera vez por el historiador James Truslow Adams en su libro The Epic of America (1931), refiere la igualdad de oportunidades y capacidad de prosperar al margen de la jerarquía social que atraería a inmigrantes de todo el mundo hacia Estados Unidos, American Way of Life (estilo de vida americano) define el estilo de vida que comenzaría tras el fin de la Segunda Guerra Mundial, caracterizada por el llamado "estado de bienestar" que introduciría a la población norteamericana de lleno en la incipiente sociedad de consumo (Cullen, 2004: 10). 
alertados por las recientes profanaciones de restos humanos de los que informa la radio local, visitan el cementerio del pequeño pueblo familiar para comprobar si la tumba de su abuelo ha sido exhumada. Después de esta parada, acuden a una antigua casa de piedra sumida en la vegetación que parece ser una antigua propiedad familiar. A pesar de que no se nos aporta gran cantidad de información, queda patente cómo este viaje es una vuelta al pasado y a la tradición a través de la visita a los restos de un antepasado y a la casa familiar. Sin embargo, en esta casa encontramos varias señales de la corrupción de este supuesto pasado idílico y campestre: una inmensa colonia de arañas que perturba a Kirk (William Vail) y el hallazgo por parte de Franklin (Paul A. Partain) de una montaña de huesos y plumas sobre el suelo, además de una especie de amuleto hecho también de restos óseos que cuelga del dintel de la puerta. Estos inquietantes descubrimientos alertan sutilmente a los personajes y al propio espectador, y muestran de forma indirecta cómo estas raíces están emponzoñadas por algún motivo que todavía no alcanzamos a ver. Cinco minutos después en el metraje, Kirk se adentra en la propiedad colindante con la intención de pedir gasolina, descubriendo allí a un gigante con máscara y delantal de carnicero que acaba con su vida a golpe de martillo.

Este primer asesinato muestra el sentido del arquetipo del viaje en el filme: jóvenes que realizan una escapada al mundo rural con la intención de apartarse de la ciudad y su problemática social, y que transitan una carretera que hace las veces de barrera física y metafórica entre la civilización y la barbarie. Al final del camino aguarda esa "América profunda" entendida como metáfora de la crisis social estadounidense (Wood, 2003: 63-85) que, en última instancia, deja entrever cómo el origen de todo mal se encuentra en las propias raíces del país. En este contexto rural, imagen antaño idílica, resuenan ecos de un pasado remoto en el que el aislamiento y la ausencia de ley conducen a sus habitantes a la perpetuación de un sistema de vida que se sostiene sin la interferencia de agentes exteriores, pero a costa de estos. Por tanto, un viaje de búsqueda de las raíces (pueblo rural, visita a la tumba del abuelo, retorno a la casa familiar de la infancia...), se convierte involuntariamente en un viaje al infierno en la tierra, una pesadilla de la que no hay retorno posible.

Antes del estreno del filme de Tobe Hooper, uno de los exploit inaugurales del gore (Cueto y Weinrichter: 87-96), 2.000 maniacos (2.000 Maniacs, Hershell Gordon Lewis, 1964) y la revolucionaria La noche de los muertos vivientes (Night of the Living Dead, George A. Romero, 1968), tuvieron en el viaje y la carretera su punto de partida. Sin embargo, en ninguna de ellas se hace un uso simbólico del arquetipo del viaje, funcionando simplemente y a diferencia de La matanza de Texas como un instrumento de apertura de la acción. Otro de los ejemplos señeros de "terror rural" y del uso subvertido del arquetipo del viaje como elemento simbólico de acercamiento al mal será Las colinas tienen ojos, en cuyo argumento se detalla de forma más específica las motivaciones tanto de las víctimas como de los verdugos. Los Carter, una familia de clase media compuesta por un matrimonio, hijos y descendencia de estos, emprenderá un viaje vacacional con destino a California en su roulotte. Desoyendo las advertencias del propietario de una gasolinera en la que repostan, deciden visitar una mina cercana famosa por sus riquezas en metales preciosos, sufriendo un accidente de camino a ella. Este viaje, pensado originalmente para conmemorar en familia las bodas de plata del matrimonio, terminará situándolos en medio de un paraje desértico rodeado de unas inquietantes colinas que son el 
hogar de un clan caníbal ${ }^{5}$ cuyo alimento principal son los viajeros despistados. La ruta, como en el caso anterior, les conducirá desde la seguridad y comodidad de su hogar, hasta una especie de micro-universo salvaje y primitivo en el que el tiempo no ha transcurrido en cuestiones de civilización y progreso. Esta búsqueda de la unión familiar y el ocio a través de la desconexión del bullicio de la ciudad, trae consecuencias imprevistas: el núcleo familiar queda desintegrado a raíz del asesinato de varios de sus miembros, forzando a los supervivientes a adoptar un comportamiento criminal en aras de la autopreservación.

Después de ambos títulos, la apertura de la acción a través del viaje como eje narrativo se convertiría en una constante tanto en el "terror rural" en particular, como en el horror movie en general, pasando rápidamente de la innovación al tópico y del simbolismo a la parodia. La idea subvertida de viaje como instrumento narrativo pasaría a asociarse en el ámbito del género de terror a lo rural: al situar el monstruo o la depravación al margen de la sociedad, ignorados por esta en lugares alejados y aislados, las víctimas han de realizar forzosamente un viaje que los conecte argumental y físicamente con ellos. Citaremos algunos de los ejemplos más relevantes del particular uso de este arquetipo en el "terror rural" desde mediados de la década de los setenta hasta la actualidad, un listado de filmes en los que se perdería de forma progresiva la simbología y la efectividad de los títulos iniciales. La violencia del sexo (I Spit in your Grave, Meir Zarchi, 1978), tiene como punto de partida el viaje que realiza una joven escritora a una casa de campo en busca de la soledad necesaria para conectar con su novela, una especie de búsqueda interior que será brutalmente interrumpida por unos dementes lugareños. Trampa para turistas (Tourist Trap, David Schmoeller, 1979) abre su argumento con un viaje de índole más lúdica, mostrándonos a un grupo de amigos dispuestos a pasar un fin de semana de diversión hasta que su automóvil se estropea. Después de esto, serán auxiliados por un habitante de la zona con aparentes buenas intenciones, que resulta tener como hermano a un psicópata con poderes telequinéticos.

Perteneciente a la década de los ochenta, y estructurada en torno a un viaje citaremos El día de la madre (Mother's Day, Charles Kaufman, 1980), un largometraje que hará especial hincapié en el viaje como búsqueda de la tranquilidad frente al bullicio de la ciudad: tres antiguas compañeras de universidad deciden pasar un fin de semana en un paraje natural para desconectar de las presiones del trabajo y las responsabilidades familiares, topándose de frente con el horror en forma de familia homicida. Por su parte, Los chicos del maiz (Children of the Corn, Fritz Kiersch, 1984), adaptación del cuento homónimo inserto en la novela El umbral de la noche (Night Shift, Stephen King, 1978), tiene como escenario un pequeño pueblo agrícola de Nebraska al que llegará un joven matrimonio que viaja en busca de su nuevo hogar. Accidentalmente descubrirán cómo el lugar está tomado por un grupo de niños seguidores de un extraño culto demoníaco, los cuales han sacrificado a todos los adultos en nombre de "El que camina detrás de la fila".

Después de la etapa de desinterés hacia el "terror rural" durante la década de los noventa, principalmente por el éxito de slashers de ambiente urbano en el que el

5 Inspirados en el impactante caso, instalado entre la leyenda y la realidad, de Swaney Bean, un jardinero de Edimburgo que durante el reinado de Jacobo VI se instalaría en una cueva en la que permanecería 25 años con su compañera, engendrando una familia endogámica y alimentándose de la carne de los viajeros que asaltaban (Urquhart, R.H.J.). 
asesino es el que se desplaza hacia la víctima (Higueras Flores, 2011: 22), tendría lugar una revitalización de este subgénero y con ello el uso del arquetipo de viaje subvertido. El filme Desvío al infierno (Wrong Turn, Rob Schmidt, 2003), también conocida en su título original como $\mathrm{Km}$. 666, parte de un aparatoso accidente entre dos vehículos en mitad de ninguna parte; de forma progresiva, los viajeros averiguan cómo esta colisión ha sido provocada por una especie de seres endogámicos, protagonistas de las leyendas locales, aficionados a dar caza a excursionistas. Del mismo año será La casa de los 1.000 cadáveres (House of 1000 Corpses, Rob Zombie, 2003), cuyo argumento tendrá su punto de partida en el viaje que un grupo de jóvenes emprenden con la misión de recabar datos para la realización de una guía de curiosidades de carretera. Su continuación, Los renegados del diablo (The Devil's Rejects, Rob Zombie, 2005), realizará un giro inusual en el horror movie, siendo los asesinos los que emprenden un viaje para escapar de la justicia, intercalándose en esta huida elementos tanto del género de terror, como de la road movie y el western.

\subsection{La subversión del arquetipo de viaje: el viajero en apuros}

Otra vertiente del arquetipo del viaje en el contexto del terror es la tradición del viajero que, lejos de su hogar, busca ayuda o cobijo en la casa maldita. Inspirándose en leyendas u obras literarias, encontramos algunos ejemplos en la primera etapa del género que remiten directamente a ello: El caserón de las sombras (The Old Dark House, James Whale, 1932), donde se va a plantear un novedoso uso del miedo hacia lo desconocido. Ambientada en Gales, a consecuencia de una tormenta unos viajeros se ven obligados a refugiarse en una siniestra mansión sobre la que se cierne un horror intangible (algo particular en un momento del género, en el que las películas estaban protagonizadas por monstruos). Sus habitantes, los Femm, constituyen una familia de nobles en decadencia, abandonada a todo tipo de vicios y perversiones. En la cinta Satanás (The Black Cat, Edgar G. Ulmer, 1934), el matrimonio Alison (David Manners y Julie Bishop) es conducido por el extraño Vitus Wendergast (Bela Lugosi) a una extraña casa de aspecto racionalista proyectada por su amigo y arquitecto Hjalmar Poezig (Boris Karloff), tras el accidente del tren en el que viajan. Durante su estancia en la terrorífica mansión, la joven pareja se verá involucrada en una cruenta venganza que hunde sus raíces en la Gran Guerra, y que se entremezcla con la práctica de inquietantes cultos satánicos. En otro contexto espacial y temporal se encuentra Drácula, príncipe de las tinieblas (Dracula, Prince of Darkness, Terence Fisher, 1966), un producto de la británica Hammer en la que vemos cómo unos viajeros son trasladados por un misterioso carruaje al castillo del Conde Drácula (Christopher Lee), después de ser abandonados en medio del bosque por un aterrorizado cochero (Hutchings, 1993: 98-129). En los tres casos, el destino del viaje se va a truncar por diversos motivos, principalmente meteorológicos o logísticos, obligando a los personajes a pernoctar en los sitios menos indicados.

Esta tradición se conserva en gran medida durante el período moderno del cine de terror, con ejemplos ya desde los orígenes de esta nueva etapa como Psicosis. En su argumento vemos como Marion Crane se ve obligada, a causa de la lluvia, a detener su camino para pasar la noche en un motel de carretera donde encontrará su muerte. Posteriormente, La matanza de Texas tomaría para sí esta vía argumental exponiendo a sus personajes a la carencia de gasolina, circunstancia que les obliga a pedir ayuda en la mismísima casa de los horrores. A continuación de estos filmes inaugurales, 
muchos títulos del "terror rural" emplearían el recurso del viajero en apuros como punto de partida para sus argumentos: Trampa mortal (Eaten Alive, 1976), dirigido también por Tobe Hooper, donde una serie de viajeros se ven forzados a detenerse en un sórdido motel por diversas circunstancias; la ya citada Trampa para turistas tendrá en el personaje de Mr. Slausen (Chuck Connors) el perfecto hombre de pueblo solidario, dispuesto a ayudar a unos chicos con problemas. Otro ejemplo, ya de la década de los ochenta, será Demencial (Unhinged, Don Gronquist, 1982) y el filme de producción británica Escóndete y tiembla (American Gothic, John Hough, 1988). Durante la revitalización del "terror rural" en la década del 2000, en relación al mito del "viajero en apuros" destacaremos de nuevo La casa de los 1000 cadáveres, donde la familia Firefly va a provocar un pinchazo en la rueda del vehículo de los jóvenes, con la idea de ofrecerles su ayuda y atraerlos de este modo hacia su guarida.

\section{Conclusiones}

Observamos de este modo cómo a partir del surgimiento de la modernidad en el cine de terror, específicamente con la aparición del subgénero que hemos denominado de "terror rural", el arquetipo del viaje sufre una definitiva subversión en su asociación con esa "América profunda" que retratan filmes como los citados La matanza de Texas o Las colinas tienen ojos, convirtiéndose en sucesivas décadas en un tópico de este género. El viaje de búsqueda de los orígenes naturales como válvula de escape de la crisis social conduce a la generación del baby boom (Váquez de Prada, 2008: 140) a toparse inesperadamente con ese mal endémico que anida en las raíces culturales y sociales de Estados Unidos.

El arquetipo de viaje, entendido como uno de los ingredientes básicos del sustrato cultural estadounidense, se convierte de esta manera en el medio metafórico y físico a través del cual accedemos al auténtico reverso tenebroso de la cultura estadounidense, un mundo donde el horror siempre aguarda tras la máscara de la hospitalidad por la que se conoce a los habitantes de las pequeñas comunidades de este país. Podemos estructurar, por tanto, la subversión de este arquetipo en el cine de "terror rural" moderno en dos vertientes:

Por un lado, aquellos filmes donde el viaje funciona como un instrumento narrativo de apertura de la acción, como en el caso de El motel del infierno; y por otro aquellos largometrajes donde se hace un uso simbólico del arquetipo de viaje, es decir, como metáfora sobre la que va a descansar el argumento.

En este último caso encontramos dos tipologías: la subversión del arquetipo a través de la recreación de un viaje sin retorno, tal y como observamos en La matanza de Texas o Las colinas tienen ojos; y una línea secundaria que aborda la temática del viajero en apuros, como es el caso de Trampa mortal o Trampa para turistas. En ambos casos se realiza un uso subvertido de las connotaciones tradicionales del arquetipo de viaje, perdiendo los valores que en su asociación a la cultura norteamericana remitían a conceptos fundacionales, religiosos y triunfantes. 


\section{Bibliografía}

Abella, R. (1990). La conquista del Oeste. Barcelona: Planeta.

Altman, R. (2000). Los géneros cinematográficos. Barcelona: Paidós.

Astre, G.A. y Hoarau, A.P. (1976). El universo del western. Madrid: Fundamentos.

Balló, J. y Pérez, X. (1995). La semilla inmortal. Los argumentos universales en el cine. Barcelona: Anagrama.

Barrio, J. M. (2004). "El viaje como génesis y arquetipo cultural de la literatura norteamericana" en Mariño, F. M. y Olivia Herrer, M. (Eds.). (2004). El viaje en la literatura occidental. Valladolid: Universidad de Valladolid.

Bradford, W. (1994). De la plantación de Plymouth. León: Universidad de León.

Clellon Holmes, J. (1997). La Generación Beat. León: Universidad de León.

Clemente Fernández, M. D. (2009). El héroe del western. América vista por sí misma. Madrid: Universidad Complutense de Madrid.

Cohan, S. y Hark, I. R. (eds.) (1997). The Road Movie Book. London: Routledge.

Conn, P. (1998). La literatura norteamericana. Cambridge: Cambridge University Press.

Correa, J.(2006). "El Road Movie: Elementos para la definición de un género cinematográfico", Cuadernos de Música, Artes Visuales, Artes Escénicas, n² 2 , Universidad Pontificia Javeriana, Bogotá D.C., pp. 270-301.

Cullen, J. (2004). The American Dream: A Short History of an Idea that Shaped a Nation. New York: Oxford University.

Cueto, R. y Weinrichter, A. (eds.). (2004). Dentro y fuera de Hollywood. La tradición independiente del cine americano. Valencia: Institut Valencià de Cinematografía Ricardo Muñoz Suay.

De Fez, D. (2007). Películas clave de cine de terror moderno. Barcelona: Robinbooks.

Degler, C. N. (1986). Historia de los EE.UU. La formación de una potencia. Barcelona: Ariel.Delgado, C. y Clemente, C. (eds.) (2013). Identidad y disidencia en la cultura estadounidense. Valencia: Univesitat de València.

Derry, C. (1977). Dark Dreams. The Horror Films from "Psycho" to "Jaws". Nueva Jersey:Barnes and Co.

Estévez-Saá, J. y Arriaga Flórez, M. (Eds.) (2005). Cultura y literatura popular: manifestaciones y aproximaciones en (con)textos irlandeses, angloamericanos y otros. Sevilla: Arcibel.

Emerson, E. (1984). El auténtico Mark Twain. Barcelona: Montesinos.

Fernández Cuenca, C. (1976). El cine de terror de la Universal. Madrid: Filmoteca Nacional de España.

Fernández Sampedro, M. G. (2008). El viaje en la ficción norteamericana. Símbolos e identidades. Valencia: Universitat de Valéncia.

Foster, S. (Ed.) (2013). British North America in the Seventeenth and Eighteenth Centuries. Oxford: Oxford University Press.

González Serrano, P. (1999). “Catábasis y resurrección”, Espacio, Tiempo y Forma, Historia Antigua, Serie II, núm. 12, pp. 1-3.

O’Gorman, E. (1958). El proceso de la invención de América. Mexico: Fondo de Cultura Económica. 
Hawgood, J. A. (1967). The American West. London: Frontier.

Hernández Alonso, J. J. (2002). Los Estados Unidos: historia y cultura. Salamanca: Alamar. Higueras Flores, R. (2011). Slasher Films: violencia carnal. Barcelona: Quarentena.

Horsman, R. (1985). La raza y el Destino Manifiesto. Orígenes del anglosajonismo racial norteamericano. México: Fondo de Cultura Económica.

Huber, P. (1995). "A Short History of Redneck: The Fashioning of a Southern White Masculine Identity”, Southern Cultures, vol.1, núm. 2, pp. 145-166. Recuperado en http:// muse.jhu.edu/article/425942 (Fecha acceso: 1/09/2017).

Hughes, R. (2001). Visiones de América: la historia épica del arte moderno. Barcelona: Galaxia Gutenberg.

Hutchings, P. (1993). Hammer and Beyond: The British Horror Film. Manchester: Manchester University Press.

Isenberg, N. (2016). White Trash: 400 Years Untold History of Class in America. New York: Viking.

Lamarca Margalef, J. (1989). William Faulkner. Movimiento, cambio y modificación. Barcelona: PPU (Tesis Doctoral).

Losilla, Carlos (1993). El cine de terror. Una introducción. Barcelona: Paidós.

Manuel Cuenca, C. (1994). Mito e innovación en la narrativa estadounidense del Nuevo Sur. Valencia: Universitat de València.

Middleton, R. (1996). Colonial America: a history, 1585-1776. Cambridge (Massachusetts): Blackwell.

Planes Pedreo, J. (eds.) (2012). Regreso al Motel Bates. Un estudio monográfico de Psicosis. Bilbao: Mensajero.

Platt, R. H. (1973). Wilderness: The Discovery of a Continent of Wonder. Westport: Greenwood.

Reis, E. (1999). Damned Women: Sinners and Witches in Puritan New England. New York:

Cornell University.

Ruiz Aja, L. (2007). La contracultura, ¿Qué fue? ¿Qué queda? Los movimientos juveniles del 68 y sus repercusiones socio-politicas en la actualidad. Madrid: Mandala.

Schaefer, E. (1999). Blood! Daring! Schoking! True! A History of Exploitation Films. London: Duke University Press.

Swartz, O. (1999). The View from On the Road: the Retorical Vision of Jack Kerouac. Carbondale: Southern Illinois University.

Trías, E. (1974). Drama e identidad. Barcelona: Barral.

Trocmé, H. (1983). Los americanos y su arquitectura. Madrid: Cátedra.

Urquhart, R.H.J. (2002): “Sawney Bean: Myth or Myth", Ayrshire Notes, no 23. Recuperado de www.ayrshirehistory.org. (23-8-2017).

Wood, R. (2003). Hollywood from Vietnam to Reagan... and Beyond. Columbia: Columbia University. 